\title{
Review Article \\ Impact of Physical Activity Intervention Programs on Self-Efficacy in Youths: A Systematic Review
}

\author{
Rosa Cataldo, ${ }^{1}$ Janice John, ${ }^{1}$ Latha Chandran, ${ }^{2}$ Susmita Pati, ${ }^{1}$ and A. Laurie W. Shroyer ${ }^{2,3}$ \\ ${ }^{1}$ Department of Pediatrics, Long Island Children's Hospital, Stony Brook University Medical Center, 101 Nicolls Road, HSC Level T11, \\ Room 020, Stony Brook, NY 11794-8111, USA \\ ${ }^{2}$ Undergraduate Medical Education, Stony Brook University Medical Center, Stony Brook, NY 11794-8111, USA \\ ${ }^{3}$ Departments of Preventive Medicine and Surgery, Stony Brook University Medical Center, Stony Brook, NY 11794-8111, USA
}

Correspondence should be addressed to Rosa Cataldo; rosa.cataldo@sbumed.org

Received 18 July 2012; Accepted 14 August 2012

Academic Editors: M. G. Matos and S. Straube

Copyright (C) 2013 Rosa Cataldo et al. This is an open access article distributed under the Creative Commons Attribution License, which permits unrestricted use, distribution, and reproduction in any medium, provided the original work is properly cited.

Lack of physical activity has contributed to the nation's childhood obesity crisis, but the impact of physical activity on self-efficacy as a mediator of behavior change has not been examined. This systematic review (SR) describes the published evidence related to the impact of physical activity intervention programs on self-efficacy among youths. From January 2000 to June 2011, the Preferred Reporting Items for Systematic Reviews and Meta-Analyses (PRISMA) standards were used to identify publications from PubMed, PsychInfo, Web of Knowledge, and the Cochran Database of Systematic Reviews. The Cochrane Population, Intervention, Control, Outcome, Study Design (PICOS) approach guided this SR articles selection and evaluation process. Of the 102 publications screened, 10 original studies matched the SR inclusion criteria. The types of physical activity interventions and self-efficacy assessments for these 10 studies were diverse. Of the 10 included articles, 6 articles identified an improvement in post-self-efficacy assessments compared to baseline and 4 showed no effect. In conclusion, physical activity intervention programs may improve self-efficacy in youths. A standardized approach to classify and measure self-efficacy is required. Further research is needed to quantify the association of self-efficacy ratings after completing physical activity interventions with objective health improvements, such as weight loss.

\section{Introduction}

The prevalence of childhood obesity has increased dramatically in the United States (US) the last 20 years. After age gender-based adjustments, more than $30 \%$ of US children and adolescents surveyed in 2007-2008 were overweight with a body mass index (BMI) greater than the 85th percentile [1] . Young Americans suffer increasing morbidity from chronic diseases associated with obesity before reaching adulthood [2]. Although the etiology of obesity is multifactorial, weight loss can be achieved by diet and activity behavior modification [3]. In order to sustain weight loss, health behavior modifications must become lifestyle changes.

Self-efficacy, a construct of Albert Bandura's social cognitive theory (SCT), is defined as the belief in one's own ability to achieve actions necessary to produce a desired effect [4]. It relates to an individual's confidence in achieving and maintaining behavioral change. Hence, it is reasonable to anticipate that physical activity intervention programs may benefit from incorporating SCT modifications and to evaluate self-efficacy as a component in determining behavioral change. Various types of self-efficacy as a mediator of behavioral change toward physical activity interventions have been described in the literature [5].

Self-efficacy has been described as a predictor of physical activity intervention outcomes rather than an independent outcome. Authors have concluded that self-efficacy served as a covariate, which impacted other psychosocial factors and indirectly influenced the success of an intervention [6]. Several original articles as well as reviews have supported the model that self-efficacy functioned as a potential mediator, within various types of physical activity programs in children [7-10]. 

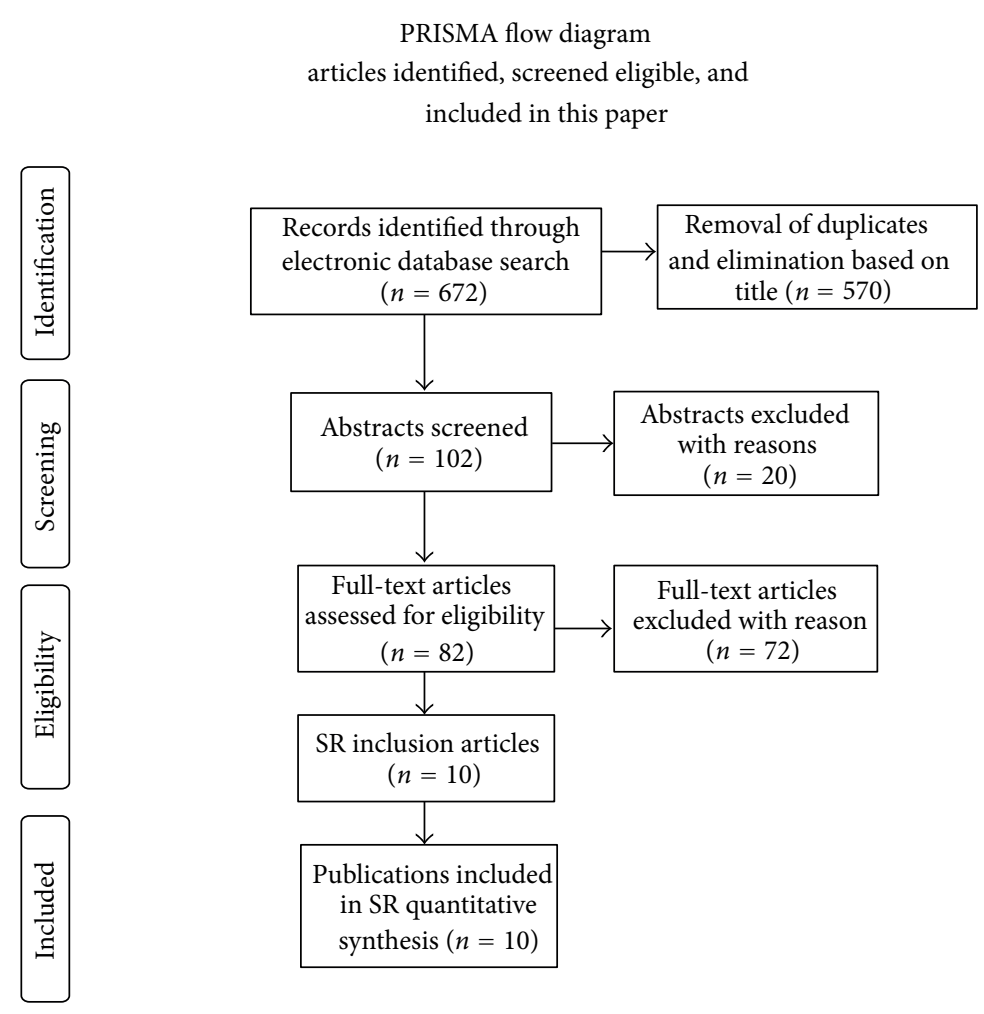

Figure 1

Although improved self-efficacy has been associated with the compliance of health behavior modification interventions, few studies indicate that the intervention may influence self-efficacy. The directionality of the interaction between physical activity interventions and self-efficacy has not been clearly established. One review did report the effect of physical activity intervention outcomes on self-efficacy as a potential mediator of behavioral change in 4-12 yearold children from 1985 to 2006 [11]. While useful, the age parameters limited the literature selection in the prior review. Additionally, the literature has not been revised to date. The potential for physical activity programs to facilitate self-efficacy and promote health behavior change remains: self-efficacy may be the transformational "missing link" to innovatively address the growing obesity crisis.

This SR primary objective was to determine if physical activity related programs were associated with improved selfefficacy in children and adolescents (5-18 years old). Given the potential to impact long-term health for children and adolescents, a secondary objective was to evaluate the effect of physical activity self-efficacy ratings upon weight reduction goals.

\section{Methods}

A protocol using the PRISMA standards was completed prior to initiating the literature search. Database searches were performed using PubMed, Web of Knowledge, PsychInfo, and the Cochran Database of Systematic Reviews (January 2000June 2011). All appropriate titles and abstracts were reviewed per study inclusion/exclusion criteria. Due to a judicious electronic search, nonelectronic sources of literature were not considered. A detailed search strategy including search terms and limitations is listed in Appendix. Only those articles written in English were appraised. The Cochrane PICOS approach was applied to select the articles included (Figure 1).

To meet the SR inclusion criteria, each publication must have included a subject population of children and adolescents (5-18 years). In evaluating these publications, a special emphasis was placed stratifying the data abstracted for the subpopulations of overweight youths. Publications were excluded if participants had a medical illness.

The articles reviewed were required to include a structured physical activity program lasting 4 weeks or more. School and community-based physical activity incorporating individual or group activities were included. Types of physical activity considered for this paper included: cardiovascular activity, resistance training, or modifications of physical education classes. Programs that included exercise exclusively or in conjunction with nutrition and psychosocial factors were considered. When provided, the level of physical activity was classified as moderate, moderate to vigorous, or vigorous preferably using metabolic equivalents (METs) rating. Publications were not required to document energy cost of physical activity, as this would have significantly limited the paper. Exclusively web-based programs were eliminated from the paper due to entirely self-reported assessments of physical activity.

All publications reviewed were required to include either a comparison or a control group. The type of comparison 
group permitted was liberal. The study participants may have been compared to subjects of another separate program, which was not coordinated contemporaneously. Comparisons may have also included groups that underwent an assessment period where there was no concurrent intervention, but then served as future intervention groups.

The outcome measures for this SR included any selfreported physical activity self-efficacy and were required to be stated within the hypothesis or objectives of the study. Other motivational variables may have been included within the articles but were not addressed in this SR. All included publications must have identified statistically significant improvements (designated a priori), of self-efficacy after completion of the intervention. Studies that assessed objective "success" measures related to body weight, body mass index or body composition were accepted but not required as part of the SR inclusion criteria.

To assure the quality of the study findings reported, the Oxford Centre for Evidence-Based Medicine (Levels of Evidence) 5-level hierarchical tool was used. Only studies with Oxford Centre for Evidence-Based Medicine levels of 3 or higher were reported [12]. Hence, all articles used either a randomized control trial approach, a quasiexperimental, or observational study design. The experimental studies were further appraised with an assessment developed by Jadad et al. to grade clinical trials [13]. A slight modification of the Jadad scoring approach was used to assess the quasiexperimental studies. For the articles meeting inclusion criteria, Table 1 identifies each reviewed study's characteristics including all PICOS components.

As an assessment of inter-rater reliability, two authors independently reviewed each publication using a standardized data capture form with definitions to evaluate if all SR article inclusion/exclusion criteria were met as well as to appraise the quality.

\section{Results}

3.1. Screening and Identification. Search strategies of the initial abstract screening identified 102 publications (Figure 1). Interventional, observational studies, reviews, and a metaanalysis were represented within the screened articles. Of the 102 screened publications, 10 original studies (11 articles) matched the final PICOS SR inclusion criteria [14-23]. One group of investigators used the same study population, study design, and data analysis methods to measure self-efficacy in two different publications. The two articles differed in addressing other psychosocial variables as well as how the multiple potential predictors for outcomes may have affected one another. These two articles were accounted for only once in this SR results and population size data to avoid overweighting of the findings [17, 24].

Seven interventional studies met all the inclusion criteria from the 20 screened interventional articles, yielding a $35 \%$ inclusion rate [17-24]. Three observational studies met all of the inclusion criteria from 70 screened articles, yielding a $4 \%$ inclusion rate [14-16].

A comprehensive list of the eliminated articles with rationale for exclusion and references is represented in Table 5.
Based upon the listed exclusion criteria: 15 studies did not fit the criteria for study design (16\%), 39 studies used selfefficacy as a predictor of physical activity (42\%), 26 articles (28\%) were omitted based on population age criteria, and 61 articles (65\%) did not fulfill the physical activity intervention criteria.

\subsection{PICOS Characteristics and Statistical Approaches}

3.2.1. Population. A total of 5229 school age participants were enrolled across 3 different types of settings. Important race and gender-based variations were noted. Two studies included female participants only [17, 18, 24], 3 studies were comprised exclusively of African American participants [15, 16, 23], 2 studies included a majority of African American participants $[14,22]$, and one study focused upon an underserved Native American Indian population [20]. Age differences also varied across the studies. Three of the studies focused solely on children ( $<12$ years of age) [15, 20, 21], 3 studies recruited only adolescents (12 to 18 years) [17-19, 24], and 4 studies focused on both children and adolescents [14, $16,22,23]$.

3.2.2. Intervention. All of the included publications used a multidisciplinary physical activity approach. Six of the studies employed a school-based setting [17-22, 24], one incorporated an after-school setting [23], and 3 were held at a Young Men's Christian Association (YMCA) location [14-16].

The key dimensions of the physical activity intervention components such as duration, intensity, and session length were diverse. The time frame of the programs varied from 8 weeks to 3 years. Six studies reported an intermediate duration ( $\geq 12$ weeks up to 6 months) [14-16, 18, 19, 23], and 4 studies reported a longer program ( $\geq 1$ year up to 3 years) $[17,20-22,24]$. The amount of sessions per week was as follows: 1 article reported intervention 2 days per week [19], 5 articles reported physical activity at least three days per week [14-16, 22, 23], 1 article reported five days per week [18], and 3 articles did not mention how often the physical activity sessions occurred [17, 20, 21, 24]. Across these publications, the length of each physical activity session ranged from 20 minutes up to 45 minutes. The assessment of metabolic equivalents (METS) was not captured and/or reported uniformly across all studies. Of the included studies: 5 reported measurements of moderate-to-vigorous intensity $[14-16,22,23]$, one measured peak oxygen uptake $\left(\mathrm{VO}_{2} \max \right)$ [18], one measured muscular strength [19], and 3 studies did not report intensity per session $[17,20,21,24]$.

3.2.3. Comparisons. Four studies were randomized control trials (RCTs), such that the control group was randomly assigned for the analytical comparisons performed [17, 19$21,24]$. The quasiexperimental (2 middle schools [22, 23], one high school [18]) studies designated partnerships with other schools to identify grade level matched comparison groups $[18,22,23]$. One of these studies also incorporated a more refined high school student matched comparison group based upon age, gender, and race [22]. 


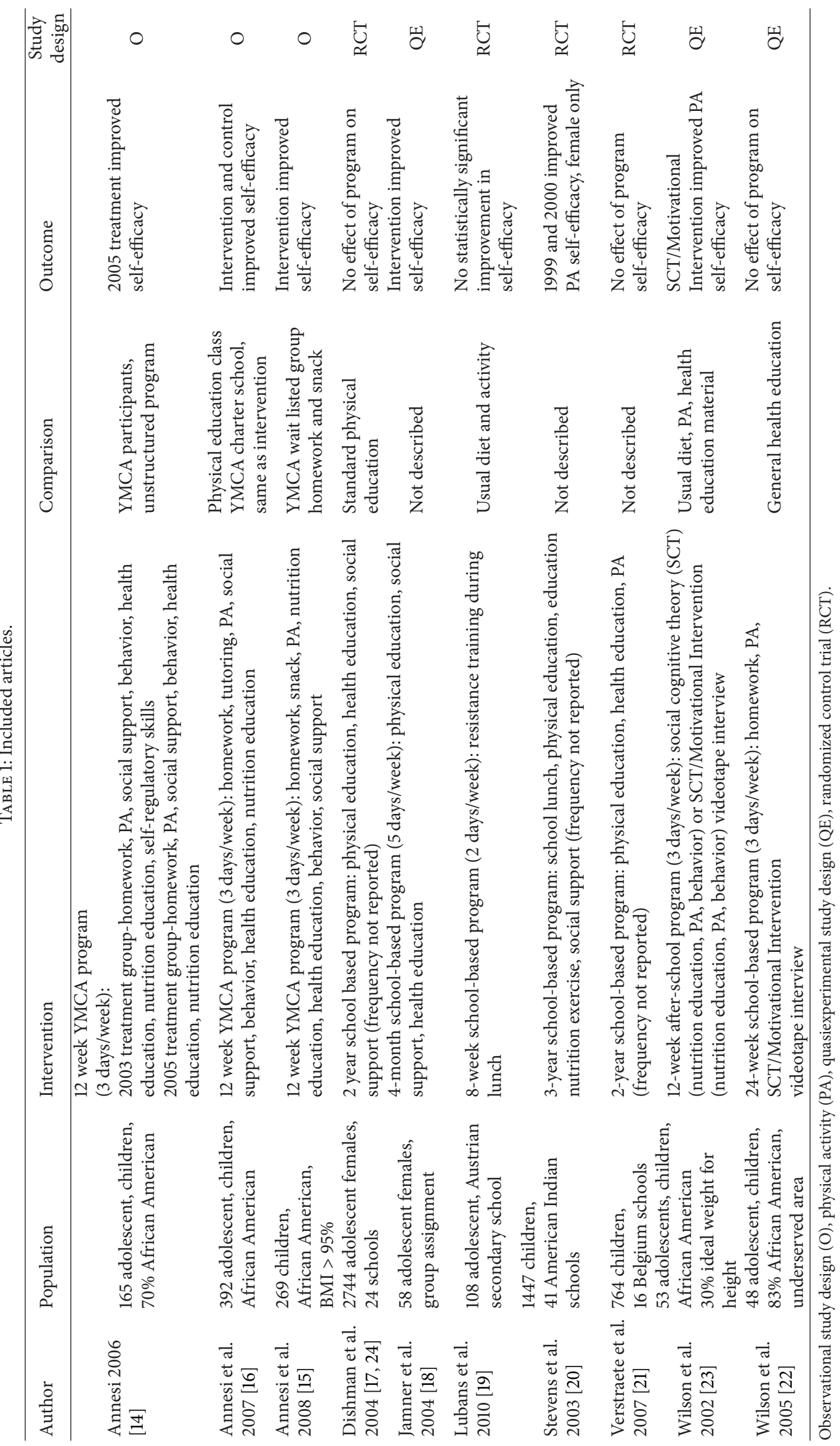


TABLE 2: Self-efficacy assessments.

\begin{tabular}{ll}
\hline Author & Self-efficacy assessment \\
\hline $\begin{array}{l}\text { Annesi 2006 [14], Annesi } \\
\text { et al. 2007 [16], Annesi et al. }\end{array}$ & Perceived barriers \\
$\begin{array}{l}\text { 2008 [15] } \\
\text { Dishman et al. 2004 [17, 24] }\end{array}$ & $\begin{array}{l}\text { Self-efficacy } \\
\text { Overcoming internal and } \\
\text { external barriers to exercise }\end{array}$ \\
Jamner et al. 2004 [18] & $\begin{array}{l}\text { Resistance training self-efficacy } \\
\text { and outcome expectancy }\end{array}$ \\
Lubans et al. 2010 [19] & $\begin{array}{l}\text { Diet and exercise self-efficacy } \\
\text { Perceived barriers and benefits } \\
\text { Stevens et al. 2003 [20] }\end{array}$ \\
Verstraete et al. 2007 [21] & $\begin{array}{l}\text { Diet and exercise self-efficacy } \\
\text { Exercise self-efficacy }\end{array}$ \\
Wilson et al. 2002 [23] & \\
Wilson et al. 2005 [22] &
\end{tabular}

For the three cohort studies, the comparisons to the physical activity related intervention programs varied. All 3 of the physical activity related interventions studied occurred in a local YMCA. In one of these studies, the comparison was a school-based physical education class [16]. The individual students were not randomized, and the students received their school's assigned intramural sports program. For the other two cohort studies, the comparison groups included: YMCA participants that were waitlisted to enroll in a future physical activity related program [15] and general YMCA participants that were not affiliated with any physical activity related intervention [14].

3.2.4. Outcomes. The "gold standard" description of selfefficacy is for perceived self-efficacy. In perceived self-efficacy, individuals have the belief that they are capable of functioning at a certain level of performance [4]. Several different categories of self-efficacy, as it applies to health-related behaviors, have been cited in the literature [25]. With the exception of the work of Annesi et al. [14-16] and Wilson et al. [22, 23], the self-efficacy assessments were not consistent across the publications included in this SR (Table 2). The lack of homogeneity of the self-efficacy surveys administered made it difficult to make in-depth comparisons to summarize the findings across studies.

The approaches to identifying statistical associations within the included articles were diverse. For each article reviewed, a $P$ value of $\leq 0.05$ was used to identify if statistically significant associations were reported. The statistical methods used include (1) descriptive assessments of central tendency and variability [22]; (2) univariate comparison using t-tests, ANOVA, and chi squared tests [23]; (3) multivariable assessments using latent variable structural equation model $[17,24]$, structural equation model [19], simplistic regression analysis [18], and more complex mixed model analysis [14, 15, 20].

3.2.5. Study Designs. Of the included articles identified for an in-depth review, the array of study designs included 4 RCTs $[17,19-21,24]$ and 3 quasiexperimental $[18,22,23]$ and 3 cohort studies [14-16]. Incorporating a range of study designs within the parameters of the methods (Oxford level $\geq 3$ ) was essential to strengthen the finding of this SR.

Per the preestablished SR protocol, the first SR project objective was to evaluate the association of physical activity intervention programs with improvements in self-efficacy. Of the 10 included studies six (60\%) found an association with improved self-efficacy after intervention [14-16, 18, 20, 23]. One of these studies reported the association for females but not for males [20].

The second SR study objective was to identify self-efficacy ratings with associated achievement of weight reduction following completion of physical activity related intervention. Although most of the studies collected baseline body weight or BMI, none of them evaluated the association of self-efficacy ratings with achievement of weight reduction (Table 3).

Two of the coauthors (R. Cataldo, J. John) analyzed each of the 102 publications. Independent assessments meeting each study's preestablished inclusion/exclusion criteria, reason for exclusion, the Oxford level of evidence grade, and the Jadad quality assessment score were recorded by both reviewers. The following concordance was observed: (1) for inclusion/exclusion decisions, there was $100 \%$ final inter-rater agreement as well as a high concordance (96\% agreement) related to the reason for exclusion; (2) for the Oxford grades (grades 1, 2, or 3), there was a 90\% agreement for ratings assigned independently; (3) of the 5 articles where Jadad ratings were assessed, there was 1 article of disagreement $(80 \%$ agreement). For the articles where initial disagreement was identified, a coauthor team consensus was reached for the data reported in Table 4.

\section{Discussion}

Based on this SR, there is moderately strong evidence to suggest that physical activity intervention programs may improve self-efficacy. Given the expansion of childhood obesity in America, the question remains: how do we elicit self-efficacy for health behavior change? This paper suggests that exercise combined with a multidisciplinary approach may positively influence self-efficacy assessments in children and adolescents. In theory, once self-efficacy is obtained for a specific behavior, there is a potential for continuation of the desired health outcome.

In efforts to campaign for a resolution of the obesity crisis, a secondary aim of this SR was to assess whether the physical activity related programs demonstrated weight reduction or weight maintenance. Of the included studies, none evaluated the association of improved self-efficacy with changes in body weight or BMI from before to after program. Due to the variable characteristics of each study design, we were unable to extrapolate any association between the improved selfefficacy ratings with objective changes in body weight or BMI.

Self-efficacy surveys have evolved to correspond to the distinct theme for which they are necessary. Of the 10 studies evaluated, only two of the authors repeatedly used the same self-efficacy assessment in their respective studies. As an 
TABLE 3: Outcome improvements.

\begin{tabular}{lcc}
\hline Author & Self-efficacy improvement & Changes in body mass \\
\hline Annesi 2006 [14], Annesi et al. 2007 [16], & Yes & Not indicated \\
Annesi et al. 2008 [15] & Yes & Not indicated \\
Dishman et al. 2004 [17, 24] & No & Not indicated \\
Jamner et al. 2004 [18] & No & Positive effect on body composition, not correlated to \\
Lubans et al. 2010 [19] & Yes, female onlycacy \\
Stevens et al. 2003 [20] & No & Not indicated \\
Verstraete et al. 2007 [21] & Yes & Not indicated \\
Wilson et al. 2002 [23] & No & Not indicated \\
Wilson et al. 2005 [22] & & Not indicated \\
\hline
\end{tabular}

TABLE 4: Oxford/Jadad rating.

\begin{tabular}{lcc}
\hline Author & Oxford & Jadad \\
\hline Annesi 2006 [14] & $2 \mathrm{~b}$ & $\mathrm{NA}$ \\
Annesi et al. 2007 [16] & $2 \mathrm{~b}$ & $\mathrm{NA}$ \\
Annesi et al. 2008 [15] & $2 \mathrm{~b}$ & $\mathrm{NA}$ \\
Dishman et al. $2004[17,24]$ & $1 \mathrm{~b}$ & $1 \mathrm{a}$ \\
Jamner et al. 2004 [18] & $1 \mathrm{~b}$ & $1 \mathrm{a}$ \\
Lubans et al. 2010 [19] & $2 \mathrm{~b}$ & $3 \mathrm{a}, \mathrm{b}, \mathrm{c}$ \\
Stevens et al. 2003 [20] & $1 \mathrm{~b}$ & $1 \mathrm{a}$ \\
Verstraete et al. 2007 [21] & $1 \mathrm{~b}$ & $2 \mathrm{a}, \mathrm{c}$ \\
Wilson et al. 2002 [23] & $2 \mathrm{~b}$ & $\mathrm{NA}$ \\
Wilson et al. 2005 [22] & $1 \mathrm{~b}$ & $1 \mathrm{a}$ \\
\hline
\end{tabular}

Oxford designation: individual RCT (1b), individual cohort study (2b). Jadad designation: (1 point assigned for each $a, b, c)$ randomization mentioned (a), randomization was appropriate (b), the fate of all participants in the study is known (c). Not applicable due to study design (NA).

important limitation, the lack of continuity of the self-efficacy surveys made it difficult to generalize the results.

There were several limitations that may present as potential biases within the cohort studies. The types of physical activity interventions were diverse (levels of activity, types of activity, differences within the instructor's level of education, and varied locations). Additionally, participants' general interest in an extramural activity (intervention group) compared to a required physical education class may have also influenced the outcome. Despite these limitations, using exclusively RCT study designs for this particular topic would have significantly limited this study's findings. Given the heterogeneity of the studies reviewed, it was difficult to make a definitive judgment of the outcomes. Although many studies indicated the importance of physical activity and nutrition education for obesity, they did not focus solely on obese children. Therefore, participant selection bias may have been a potential confounder. Although many initially reviewed articles included baseline and postphysical activity program self-efficacy assessments, few articles appraised whether the physical activity curriculum details (e.g., dose of physical activity, duration of physical activity, and/or frequency of physical activity) were associated with an improved selfefficacy. The most challenging bias was the lack of a uniform, standardized definition of self-efficacy, as well as an inconsistent approach to measuring theory. The heterogeneous characterization of the term self-efficacy (psychosocial variable, self-efficacy, perceived barriers, internal verses external barriers) may have affected and limited the search criteria for articles in this SR.

The findings of this SR suggest that there is moderately strong evidence that physical activity related programs improve self-efficacy in youths. However, based on this paper, there is insufficient evidence about the effect of physical activity related programs on weight status. Sustaining the benefits of health behavior programs, whether improved selfefficacy or objective indicators (body weight), may be a key determinant to long-term health outcomes. Factors that influence persistence of positive behavioral changes over time need further elucidation.

Further research appears warranted to clarify the relationship between physical activity programs with changes in self-efficacy and weight loss as well as long-term impacts on weight management. In addition to selection bias and a lack of true RCT, a challenge with research in this area is defining self-efficacy and having a unified measuring system or assessment tool. Policy to support health behavior interventions is necessary to optimally impact the US obesity crisis. Future physical activity related research should be expanded to include a representative sampling of school age participants across a greater diversity of school-based or socially oriented environment.

\section{Appendix}

\section{Database Search}

For the publications, all titles and abstracts were reviewed as per study inclusion/exclusion criteria.

A.1. PubMed. The selection of medical subject heading terms $(\mathrm{MeSH})$ was applied toward the PubMed search. Applying "obesity" as a MeSH term to those listed in the following diminished the number of displayed results. Additionally, it did not contribute to the number of potential inclusion articles. The MeSH term "physical activity" displayed results 
TABLE 5: Eliminated articles and references.

\begin{tabular}{|c|c|c|c|}
\hline Article & Population & $\begin{array}{l}\text { Study } \\
\text { design }\end{array}$ & $\begin{array}{c}\text { Exclusion } \\
\text { rationale }\end{array}$ \\
\hline Allison et al. [25] & $\mathrm{a}$ & $\mathrm{O}$ & NCI, SEIE \\
\hline Annesi et al. [26] & c & $\mathrm{O}$ & $\mathrm{NC}$ \\
\hline Annesi et al. [27] & c & $\mathrm{O}$ & NC, SEIE \\
\hline Annesi [28] & c & $\mathrm{O}$ & NC \\
\hline Annesi et al. [29] & c & $\mathrm{O}$ & NC \\
\hline Annesi et al. [30] & c & $\mathrm{O}$ & NC \\
\hline Annesi et al. [31] & $c$ & $\mathrm{O}$ & $\mathrm{NC}$ \\
\hline Annesi [7] & $a / c$ & M & SEIE \\
\hline Barr-Anderson et al. [32] & $\mathrm{a}$ & $\mathrm{O}$ & NCI, SEIE \\
\hline Barr-Anderson et al. [33] & a & $\mathrm{O}$ & NCI, SEIE \\
\hline Beets et al. [34] & a & $\mathrm{O}$ & NCI \\
\hline Berry et al. [35] & $\mathrm{a}$ & $\mathrm{O}$ & NCI \\
\hline Boutelle et al. [36] & A & $\mathrm{O}$ & $\mathrm{NCI}$ \\
\hline Bray [37] & $\mathrm{a} / \mathrm{A}$ & $\mathrm{O}$ & NCI \\
\hline Brown $[38]$ & $\mathrm{A}$ & $\mathrm{O}$ & NCI \\
\hline Cardon et al. [39] & $c$ & $\mathrm{O}$ & $\mathrm{NC}, \mathrm{NCI}$ \\
\hline Carels et al. [40] & $\mathrm{A}$ & $\mathrm{RCT}$ & NSE \\
\hline Courneya and McAuley [41] & A & $\mathrm{O}$ & NCI, SEIE \\
\hline de Bourdeaudhuij et al. [42] & $\mathrm{a}$ & $\mathrm{O}$ & NCI, SEIE \\
\hline Deforche et al. [43] & $\mathrm{a}$ & $\mathrm{O}$ & NC, NCI \\
\hline Dilorenzo et al. [44] & $a / c$ & $\mathrm{O}$ & NCI \\
\hline Dishman et al. [45] & $\mathrm{a} / \mathrm{c}$ & $\mathrm{O}$ & NCI, SEIE \\
\hline Dzewaltowski et al. [46] & $\mathrm{a}$ & $\mathrm{O}$ & NCI, SEIE \\
\hline Dzewaltowski et al. [47] & c & $\mathrm{O}$ & NCI, SEIE \\
\hline Epstein et al. [48] & c & QE & NCI, NSE \\
\hline Epstein et al. [49] & a & QE & NSE \\
\hline Foster et al. [50] & c & $\mathrm{O}$ & NCI \\
\hline Gao et al. [51] & $\mathrm{A}$ & $\mathrm{O}$ & NCI, SEIE \\
\hline Gillison et al. [52] & a & $\mathrm{O}$ & NCI, NSE \\
\hline Gortmaker et al. [53] & a & QE & NSE \\
\hline Hausenblas et al. [54] & $\mathrm{a}$ & $\mathrm{O}$ & NCI, SEIE \\
\hline Heitzler et al. [55] & $\mathrm{c} / \mathrm{A}$ & $\mathrm{O}$ & NCI, SEIE \\
\hline Keats et al. [56] & $\mathrm{a}$ & $\mathrm{O}$ & NCI \\
\hline Kitzman-Ulrich et al. [57] & $\mathrm{a}$ & $\mathrm{O}$ & NC, SEIE \\
\hline Kloek et al. [58] & A & $\mathrm{O}$ & NCI, SEIE \\
\hline Knöpfli et al. [59] & A & QE & NCI, NSE \\
\hline Kowal and Fortier [60] & $\mathrm{A}$ & $\mathrm{O}$ & NCI, NSE \\
\hline Lewis et al. [8] & $\mathrm{c} / \mathrm{A}$ & $\mathrm{R}$ & SEIE \\
\hline Lytle et al. [61] & $\mathrm{a} / \mathrm{c}$ & $\mathrm{O}$ & SEIE \\
\hline Maltby and Day [62] & A & $\mathrm{O}$ & NCI, NSE \\
\hline Martin et al. [63] & $\mathrm{a}$ & $\mathrm{O}$ & NSE \\
\hline Martin and McCaughtry [64] & c & $\mathrm{O}$ & NCI, SEIE \\
\hline McClaran [65] & A & $\mathrm{O}$ & $\mathrm{NC}$ \\
\hline Melnyk et al. [66] & a & $\mathrm{RCT}$ & NSE \\
\hline Mildestvedt and Meland [67] & A & $\mathrm{O}$ & NCI, NSE \\
\hline Moreno Murcia et al. [68] & $\mathrm{a}$ & $\mathrm{O}$ & NSE \\
\hline Moreno et al. [69] & A & $\mathrm{O}$ & NCI \\
\hline Motl et al. [70] & $\mathrm{a}$ & QE & NSE \\
\hline Motl et al. [71] & $\mathrm{a}$ & $\mathrm{RCT}$ & SEIE \\
\hline Murru and Ginis [72] & A & RCT & NCI, SEIE \\
\hline Nicholls et al. [73] & A & $\mathrm{O}$ & NCI, SEIE \\
\hline Nigg and Courneya [74] & $\mathrm{a}$ & $\mathrm{O}$ & NCI, SEIE \\
\hline Nigg [75] & a & $\mathrm{O}$ & NCI \\
\hline Parcel et al. [76] & a & QE & $\begin{array}{c}\text { Year prior } \\
2000\end{array}$ \\
\hline Patrick et al. [77] & $\mathrm{a}$ & QE & NCI, NSE \\
\hline Pender et al. [78] & $\mathrm{a} / \mathrm{c}$ & $\mathrm{O}$ & NCI \\
\hline Quintiliani et al. [79] & $\mathrm{a} / \mathrm{A}$ & $\mathrm{O}$ & NCI \\
\hline Raudsepp et al. [80] & $\mathrm{a}$ & $\mathrm{O}$ & NSE \\
\hline
\end{tabular}

TABLE 5: Continued.

\begin{tabular}{|c|c|c|c|}
\hline Article & Population & $\begin{array}{l}\text { Study } \\
\text { design }\end{array}$ & $\begin{array}{c}\text { Exclusion } \\
\text { rationale }\end{array}$ \\
\hline Renner et al. [81] & $\mathrm{a} / \mathrm{A}$ & $\mathrm{O}$ & NCI, SEIE \\
\hline Robbins et al. [82] & $\mathrm{c} / \mathrm{A}$ & $\mathrm{O}$ & NCI \\
\hline Robbins et al. [83] & $\mathrm{a} / \mathrm{c}$ & $\mathrm{O}$ & NCI, SEIE \\
\hline Roemmich et al. [84] & $\mathrm{a}$ & QE & NSE \\
\hline Roemmich et al. [85] & $\mathrm{a} / \mathrm{c}$ & RCT & NSE \\
\hline Rosenberg et al. [86] & $\mathrm{a}$ & RCT & NSE \\
\hline Ryan et al. [87] & $\mathrm{A}$ & $\mathrm{O}$ & NCI, NSE \\
\hline Ryan and Dzewaltowski [88] & $a / c$ & $\mathrm{O}$ & NCI, SEIE \\
\hline Sallis et al. [89] & $\mathrm{A}$ & $\mathrm{O}$ & NCI \\
\hline Sallis et al. [90] & $\mathrm{a} / \mathrm{c}$ & $\mathrm{O}$ & NSE \\
\hline Sallis et al. [9] & $\mathrm{a} / \mathrm{c}$ & $\mathrm{R}$ & SEIE \\
\hline Salmon et al. [91] & $c$ & RCT & NSE \\
\hline Salvy et al. [92] & $\mathrm{a}$ & QE & NCI, NSE \\
\hline Schneider et al. [93] & $\mathrm{A}$ & RCT & NSE \\
\hline Sherwood et al. [94] & c & RCT & SEIE \\
\hline Shields et al. [95] & $\mathrm{a}$ & $\mathrm{O}$ & NCI, SEIE \\
\hline Shields and Brawley [96] & A & $\mathrm{O}$ & NCI, SEIE \\
\hline Shrigley and Dawson [97] & A & $\mathrm{O}$ & NC \\
\hline Sothern et al. [98] & $c$ & $\mathrm{O}$ & NCI, SEIE \\
\hline Stone et al. [99] & $a / c$ & $\mathrm{R}$ & SEIE \\
\hline Strauss et al. [100] & $\mathrm{a} / \mathrm{c}$ & $\mathrm{O}$ & NCI \\
\hline Sung et al. [101] & $c$ & $\mathrm{O}$ & NCI, NSE \\
\hline Taylor et al. [102] & $\mathrm{a} / \mathrm{c}$ & $\mathrm{O}$ & NCI \\
\hline Taymoori and Lubans [103] & $\mathrm{a}$ & QE & NCI, SEIE \\
\hline Taymoori et al. [104] & a & $\mathrm{O}$ & NCI, SEIE \\
\hline Thompson et al. [105] & c & $\mathrm{O}$ & NCI, NSE \\
\hline Trost et al. [106] & c & $\mathrm{O}$ & NCI, SEIE \\
\hline Trost et al. [107] & $\mathrm{a}$ & $\mathrm{O}$ & NCI, SEIE \\
\hline Valois et al. [108] & $\mathrm{a}$ & $\mathrm{O}$ & NCI \\
\hline Watson et al. [109] & $\mathrm{a} / \mathrm{c}$ & $\mathrm{O}$ & $\mathrm{NC}, \mathrm{NCI}$ \\
\hline Wilson et al. [110] & $\mathrm{a}$ & $\mathrm{O}$ & NCI, SEIE \\
\hline Wilson et al. [111] & a & RCT & SEIE \\
\hline Wenthe et al. [112] & $\mathrm{a}$ & $\mathrm{O}$ & NCI, SEIE \\
\hline Wright et al. [113] & $\mathrm{a}$ & $\mathrm{O}$ & NCI, SEIE \\
\hline
\end{tabular}

Adults (A), adolescent (a), children (c), literature or systematic review (R), meta-analysis (M), no control group (NC), intervention criteria not fulfilled (NCI), self-efficacy not measured (NSE), observational study design (O) (includes cross-sectional study design, longitudinal design, cohorts, crossover design), quasiexperimental study design (QE), randomized control trial (RCT), self-efficacy influencing exercise (SEIE).

for "motor activity" suggesting a developmental skill rather than exercise.

(1) Exercise and self-efficacy. (2) Exercise influence on self-efficacy. (3) Exercise and motivation. (4) Exercise and behavior.

Limits: ages 0-18 years, clinical trials, reviews, randomized control trials, years 2000-2011.

A.2. Web of Knowledge. (1) Exercise and self-efficacy.

Limits: ages 0-18 years, clinical trials, reviews, randomized control trials, years 2000-2011.

\section{A.3. PsychInfo. (1) Exercise and self-efficacy.}

Limits: ages $0-18$ years, clinical trials, reviews, randomized control trials, years 2000-2011. 
A.4. Cochrane Central Register. (1) Exercise influencing selfefficacy in children and adolescents, included advance search.

\section{Conflict of Interests}

The authors declare that there is no conflict of interests.

\section{Acknowledgments}

This study was supported by the Stony Brook University School of Medicine Department of Pediatrics: Academic General Pediatrics fellowship program (Drs. Cataldo, John's, Pati's, and Chandran's support), the Stony Brook University Department of Undergraduate Medical Education (Drs. Chandran's and Shroyer's support) as well as by the Department of Preventive Medicine and Surgery (Dr. Shroyer's support). The authors wish to thank Amy Braksmajer for her critical review, constructive feedback, and editing skills. Special thanks are provided to Dr. Margaret McGovern (Chair Department of Pediatrics) for her support of the systematic review project.

\section{References}

[1] C. L. Ogden, M. D. Carroll, B. K. Kit, and K. M. Flegal, "Prevalence of obesity and trends in body mass index among US children and adolescents, 1999-2010," The Journal of the American Medical Association, vol. 307, no. 5, pp. 483-490, 2012.

[2] S. E. Barlow, "Expert committee recommendations regarding the prevention, assessment, and treatment of child and adolescent overweight and obesity: summary report," Pediatrics, vol. 120, supplement 4, pp. S164-S192, 2007.

[3] D. Nemet, S. Barkan, Y. Epstein, O. Friedland, G. Kowen, and A. Eliakim, "Short- and long-term beneficial effects of a combined dietary-behavioral-physical activity intervention for the treatment of childhood obesity," Pediatrics, vol. 115, no. 4, pp. e443-e449, 2005.

[4] A. Bandura, Self-Efficacy: The Exercise of Control, W. H. Freeman, New York, NY, USA, 1997.

[5] G. J. Ryan and D. A. Dzewaltowski, "Comparing the relationships between different types of self-efficacy and physical activity in youth," Health Education and Behavior, vol. 29, no. 4, pp. 491-504, 2002.

[6] N. E. Sherwood, W. C. Taylor, M. Treuth et al., "Measurement characteristics of activity-related psychosocial measures in 8- to 10-year-old African-American girls in the girls health enrichment multisite study (GEMS)," Preventive Medicine, vol. 38, supplement, pp. S60-S68, 2004.

[7] J. J. Annesi, "Initial body mass index and free-time physical activity moderate effects of the youth fit for life treatment in African-American pre-adolescents," Perceptual and Motor Skills, vol. 110, no. 3, pp. 789-800, 2010.

[8] B. A. Lewis, B. H. Marcus, R. R. Pate, and A. L. Dunn, "Psychosocial mediators of physical activity behavior among adults and children," American Journal of Preventive Medicine, vol. 23, no. 2, pp. 26-35, 2002.

[9] J. F. Sallis, J. J. Prochaska, and W. C. Taylor, "A review of correlates of physical activity of children and adolescents," Medicine and Science in Sports and Exercise, vol. 32, no. 5, pp. 963-975, 2000.
[10] E. J. Stone, T. L. McKenzie, G. J. Welk, and M. L. Booth, "Effects of physical activity interventions in youth: review and synthesis," American Journal of Preventive Medicine, vol. 15, no. 4, pp. 298-315, 1998.

[11] J. Salmon, H. Brown, and C. Hume, "Effects of strategies to promote children's physical activity on potential mediators," International Journal of Obesity, vol. 33, supplement 1, pp. S66S73, 2009.

[12] B. Phillips, C. Ball, D. Sackett, D. Badenoch, S. Straus, B. Haynes et al., "Levels of evidence," British Journal of Urology International, vol. 107, no. 2, pp. 348-348, 2011.

[13] A. R. Jadad, R. A. Moore, D. Carroll et al., "Assessing the quality of reports of randomized clinical trials: is blinding necessary?" Controlled Clinical Trials, vol. 17, no. 1, pp. 1-12, 1996.

[14] J. J. Annesi, "Relations of physical self-concept and self-efficacy with frequency of voluntary physical activity in preadolescents: implications for after-school care programming," Journal of Psychosomatic Research, vol. 61, no. 4, pp. 515-520, 2006.

[15] J. J. Annesi, A. D. Faigenbaum, W. L. Westcott, and A. E. Smith, "Relations of self-appraisal and mood changes with voluntary physical activity changes in African American preadolescents in an after-school care intervention," Journal of Sports Science and Medicine, vol. 7, no. 2, pp. 260-268, 2008.

[16] J. J. Annesi, A. D. Faigenbaum, W. L. Westcott, A. E. Smith, J. L. Unruh, and F. G. Hamilton, "Effects of the Youth Fit For Life protocol on physiological, mood, self-appraisal, and voluntary physical activity changes in African American preadolescents: contrasting after-school care and physical education formats," International Journal of Clinical and Health Psychology, vol. 7, no. 3, pp. 641-659, 2007.

[17] R. K. Dishman, R. W. Motl, R. Saunders et al., "Self-efficacy partially mediates the effect of a school-based physical-activity intervention among adolescent girls," Preventive Medicine, vol. 38, no. 5, pp. 628-636, 2004.

[18] M. S. Jamner, D. Spruijt-Metz, S. Bassin, and D. M. Cooper, "A controlled evaluation of a school-based intervention to promote physical activity among sedentary adolescent females: project FAB," Journal of Adolescent Health, vol. 34, no. 4, pp. 279-289, 2004.

[19] D. R. Lubans, E. J. Aguiar, and R. Callister, "The effects of free weights and elastic tubing resistance training on physical selfperception in adolescents," Psychology of Sport and Exercise, vol. 11, no. 6, pp. 497-504, 2010.

[20] J. Stevens, M. Story, K. Ring et al., "The impact of the pathways intervention on psychosocial variables related to diet and physical activity in American Indian schoolchildren," Preventive Medicine, vol. 37, supplement 1, pp. S70-S79, 2003.

[21] S. J. M. Verstraete, G. M. Cardon, D. L. R. de Clercq, and I. M. M. de Bourdeaudhuij, "A comprehensive physical activity promotion programme at elementary school: the effects on physical activity, physical fitness and psychosocial correlates of physical activity," Public Health Nutrition, vol. 10, no. 5, pp. 477484, 2007.

[22] D. K. Wilson, A. E. Evans, J. Williams, G. Mixon, J. R. Sirard, and R. Pate, "A preliminary test of a student-centered intervention on increasing physical activity in underserved adolescents," Annals of Behavioral Medicine, vol. 30, no. 2, pp. 119-124, 2005.

[23] D. K. Wilson, R. Friend, N. Teasley, S. Green, I. L. Reaves, and D. A. Sica, "Motivational versus social cognitive interventions for promoting fruit and vegetable intake and physical activity in African American adolescents," Annals of Behavioral Medicine, vol. 24, no. 4, pp. 310-319, 2002. 
[24] R. K. Dishman, R. W. Motl, R. Saunders et al., "Enjoyment mediates effects of a school-based physical-activity intervention," Medicine and Science in Sports and Exercise, vol. 37, no. 3, pp. 478-487, 2005.

[25] K. R. Allison, J. J. M. Dwyer, and S. Makin, "Self-efficacy and participation in vigorous physical activity by high school students," Health Education and Behavior, vol. 26, no. 1, pp. 1224, 1999.

[26] J. J. Annesi, W. L. Westcott, A. D. Faigenbaum, and J. L. Unruh, "Effects of a 12-week physical activity protocol delivered by YMCA after-school counselors (youth fit for life) on fitness and self-efficacy changes in 5-12-year-old boys and girls," Research Quarterly for Exercise and Sport, vol. 76, no. 4, pp. 468-476, 2005.

[27] J. J. Annesi, A. D. Faigenbaum, and W. L. Westcott, "Relations of transtheoretical model stage, self-efficacy, and voluntary physical activity in african American preadolescents," Research Quarterly for Exercise and Sport, vol. 81, no. 2, pp. 239-244, 2010.

[28] J. J. Annesi, "Relations of age with changes in self-efficacy and physical self-concept in preadolescents participating in a physical activity intervention during afterschool care," Perceptual and Motor Skills, vol. 105, no. 1, pp. 221-226, 2007.

[29] J. J. Annesi, A. D. Faigenbaum, W. L. Westcott, A. E. Smith, and G. Dixon, "Effects of the youth fit for life protocol on physiological factors, mood, self-appraisal, voluntary physical activity, and fruit and vegetable consumption in children enrolled in ymca after-school care," Journal of Social, Behavioral, and Health Sciences, vol. 1, pp. 86-102, 2007.

[30] J. J. Annesi, J. C. Moore, and G. M. Dixon, "Correlates of changes in voluntary physical activity associated with the youth fit for life intervention during after-school care," Psychological Reports, vol. 102, no. 3, pp. 911-919, 2008.

[31] J. J. Annesi, G. Tennant, W. L. Westcott, A. D. Faigenbaum, and A. E. Smith, "Effects of the youth fit for life protocol on physiological, psychological, and behavioral factors at ymca calgary after-school care sites," Psychological Reports, vol. 104, no. 3, pp. 879-895, 2009.

[32] D. J. Barr-Anderson, D. R. Young, J. F. Sallis et al., "Structured physical activity and psychosocial correlates in middle-school girls," Preventive Medicine, vol. 44, no. 5, pp. 404-409, 2007.

[33] D. J. Barr-Anderson, D. Neumark-Sztainer, K. H. Schmitz et al., "But i like PE: factors associated with enjoyment of physical education class in middle school girls," Research Quarterly for Exercise and Sport, vol. 79, no. 1, pp. 18-27, 2008.

[34] M. W. Beets, K. H. Pitetti, and L. Forlaw, "The role of selfefficacy and referent specific social support in promoting rural adolescent girls' physical activity," American Journal of Health Behavior, vol. 31, no. 3, pp. 227-237, 2007.

[35] T. Berry, P. J. Naylor, and J. Wharf-Higgins, "Stages of change in adolescents: an examination of self-efficacy, decisional balance, and reasons for relapse," Journal of Adolescent Health, vol. 37, no. 6, pp. 452-459, 2005.

[36] K. N. Boutelle, R. W. Jeffery, and S. A. French, "Predictors of vigorous exercise adoption and maintenance over four years in a community sample," International Journal of Behavioral Nutrition and Physical Activity, vol. 1, article 13, 2004.

[37] S. R. Bray, "Self-efficacy for coping with barriers helps students stay physically active during transition to their first year at a university," Research Quarterly for Exercise and Sport, vol. 78, no. 2, pp. 61-70, 2007.
[38] S. A. Brown, "Measuring perceived benefits and perceived barriers for physical activity," American Journal of Health Behavior, vol. 29, no. 2, pp. 107-116, 2005.

[39] G. Cardon, R. Philippaerts, J. Lefevre et al., "Physical activity levels in 10- to 11-year-olds: clustering of psychosocial correlates," Public Health Nutrition, vol. 8, no. 7, pp. 896-903, 2005.

[40] R. A. Carels, L. Darby, H. M. Cacciapaglia et al., "Using motivational interviewing as a supplement to obesity treatment: a stepped-care approach," Health Psychology, vol. 26, no. 3, pp. 369-374, 2007.

[41] K. S. Courneya and E. McAuley, "Are there different determinants of the frequency, intensity, and duration of physical activity?" Behavioral Medicine, vol. 20, no. 2, pp. 84-90, 1994.

[42] I. de Bourdeaudhuij, J. Lefevre, B. Deforche, K. Wijndaele, L. Matton, and R. Philippaerts, "Physical activity and psychosocial correlates in normal weight and overweight 11 to 19 year olds," Obesity Research, vol. 13, no. 6, pp. 1097-1105, 2005.

[43] B. Deforche, I. de Bourdeaudhuij, A. Tanghe, A. P. Hills, and P. D. Bode, "Changes in physical activity and psychosocial determinants of physical activity in children and adolescents treated for obesity," Patient Education and Counseling, vol. 55, no. 3, pp. 407-415, 2004.

[44] T. M. Dilorenzo, R. C. Stucky-Ropp, J. S. Vander Wal, and H. J. Gotham, "Determinants of exercise among children. II. A longitudinal analysis," Preventive Medicine, vol. 27, no. 3, pp. 470-477, 1998

[45] R. K. Dishman, D. P. Hales, J. F. Sallis et al., "Validity of socialcognitive measures for physical activity in middle-school girls," Journal of Pediatric Psychology, vol. 35, no. 1, pp. 72-88, 2010.

[46] D. A. Dzewaltowski, K. Karteroliotis, G. Welk, J. A. Johnston, D. Nyaronga, and P. A. Estabrooks, "Measurement of self-efficacy and proxy efficacy for middle school youth physical activity," Journal of Sport and Exercise Psychology, vol. 29, no. 3, pp. 310332, 2007.

[47] D. A. Dzewaltowski, K. S. Geller, R. R. Rosenkranz, and K. Karteroliotis, "Children's self-efficacy and proxy efficacy for after-school physical activity," Psychology of Sport and Exercise, vol. 11, no. 2, pp. 100-106, 2010.

[48] L. H. Epstein, J. N. Roemmich, F. G. Saad, and E. A. Handley, "The value of sedentary alternatives influences child physical activity choice," International Journal of Behavioral Medicine, vol. 11, no. 4, pp. 236-242, 2004.

[49] L. H. Epstein, J. N. Roemmich, R. A. Paluch, and H. A. Raynor, "Physical activity as a substitute for sedentary behavior in youth," Annals of Behavioral Medicine, vol. 29, no. 3, pp. 200209, 2005.

[50] K. E. Foster, T. K. Behrens, A. L. Jager, and D. A. Dzewaltowski, "Effect of elimination games on physical activity and psychosocial responses in children," Journal of Physical Activity and Health, vol. 7, no. 4, pp. 475-483, 2010.

[51] Z. Gao, J. C. Hannon, and X. Yi, "Examining the role of selfefficacy and three types of outcome expectations in weight training," Perceptual and Motor Skills, vol. 105, no. 3 I, pp. 707713, 2007.

[52] F. B. Gillison, M. Standage, and S. M. Skevington, "Relationships among adolescents' weight perceptions, exercise goals, exercise motivation, quality of life and leisure-time exercise behaviour: a self-determination theory approach," Health Education Research, vol. 21, no. 6, pp. 836-847, 2006.

[53] S. L. Gortmaker, L. W. Y. Cheung, K. E. Peterson et al., "Impact of a school-based interdisciplinary intervention on diet and 
physical activity among urban primary school children: eat well and keep moving," Archives of Pediatrics and Adolescent Medicine, vol. 153, no. 9, pp. 975-983, 1999.

[54] H. A. Hausenblas, C. R. Nigg, D. S. Downs, D. S. Fleming, and D. P. Connaughton, "Perceptions of exercise stages, barrier self-efficacy, and decisional balance for middle-level school students," Journal of Early Adolescence, vol. 22, no. 4, pp. 436454, 2002.

[55] C. D. Heitzler, L. A. Lytle, D. J. Erickson, D. Barr-Anderson, J. R. Sirard, and M. Story, "Evaluating a model of youth physical activity," American Journal of Health Behavior, vol. 34, no. 5, pp. 593-606, 2010.

[56] M. R. Keats, S. N. Culos-Reed, K. S. Courneya, and M. McBride, "Understanding physical activity in adolescent cancer survivors: an application of the theory of planned behavior," Psycho-Oncology, vol. 16, no. 5, pp. 448-457, 2007.

[57] H. Kitzman-Ulrich, D. K. Wilson, M. L. van Horn, and H. G. Lawman, "Relationship of body mass index and psychosocial factors on physical activity in underserved adolescent boys and girls," Health Psychology, vol. 29, no. 5, pp. 506-513, 2010.

[58] G. C. Kloek, F. J. van Lenthe, P. W. M. van Nierop, C. T. M. Schrijvers, and J. P. Mackenbach, "Stages of change for moderateintensity physical activity in deprived neighborhoods," Preventive Medicine, vol. 43, no. 4, pp. 325-331, 2006.

[59] B. H. Knöpfli, T. Radtke, M. Lehmann et al., "Effects of a multidisciplinary inpatient intervention on body composition, aerobic fitness, and quality of life in severely obese girls and boys," Journal of Adolescent Health, vol. 42, no. 2, pp. 119-127, 2008.

[60] J. Kowal and M. S. Fortier, "Motivational determinants of flow: contributions from self-determination theory," Journal of Social Psychology, vol. 139, no. 3, pp. 355-368, 1999.

[61] L. A. Lytle, D. M. Murray, K. R. Evenson et al., "Mediators affecting girls' levels of physical activity outside of school: findings from the trial of activity in adolescent girls," Annals of Behavioral Medicine, vol. 38, no. 2, pp. 124-136, 2009.

[62] J. Maltby and L. Day, "The relationship between exercise motives and psychological well-being," The Journal of Psychology, vol. 135, no. 6, pp. 651-660, 2001.

[63] A. J. Martin, D. V. Tipler, H. W. Marsh, C. E. Richards, and M. R. Williams, "Assessing multidimensional physical activity motivation: a construct validity study of high school students," Journal of Sport and Exercise Psychology, vol. 28, no. 2, pp. 171192, 2006

[64] J. J. Martin and N. McCaughtry, "Using social cognitive theory to predict physical activity in inner-city African American school children," Journal of Sport and Exercise Psychology, vol. 30, no. 4, pp. 378-391, 2008.

[65] S. R. McClaran, "The effectiveness of personal training on changing attitudes towards physical activity," Journal of Sports Science and Medicine, vol. 2, no. 1, pp. 10-14, 2003.

[66] B. M. Melnyk, L. Small, D. Morrison-Beedy et al., "The COPE healthy lifestyles TEEN program: feasibility, preliminary efficacy, \& lessons learned from an after school group intervention with overweight adolescents," Journal of Pediatric Health Care, vol. 21, no. 5, pp. 315-322, 2007.

[67] T. Mildestvedt and E. Meland, "Examining the "Matthew Effect" on the motivation and ability to make lifestyle changes in 217 heart rehabilitation patients," Scandinavian Journal of Public Health, vol. 35, no. 2, pp. 140-147, 2007.
[68] A. Moreno Murcia, G. Cervello, and C. Gonzalez-Cutre, "Young atletes motivational profile," Journal of Sports Science and Medicine, vol. 6, no. 3, pp. 172-179, 2007.

[69] J. A. Moreno, D. González-Cutre, A. Sicilia, and C. M. Spray, "Motivation in the exercise setting: integrating constructs from the approach-avoidance achievement goal framework and selfdetermination theory," Psychology of Sport and Exercise, vol. 11, no. 6, pp. 542-550, 2010.

[70] R. W. Motl, R. K. Dishman, R. Saunders, M. Dowda, G. Felton, and R. R. Pate, "Measuring enjoyment of physical activity in adolescent girls," American Journal of Preventive Medicine, vol. 21, no. 2, pp. 110-117, 2001.

[71] R. W. Motl, R. K. Dishman, D. S. Ward et al., "Comparison of barriers self-efficacy and perceived behavioral control for explaining physical activity across 1 year among adolescent girls," Health Psychology, vol. 24, no. 1, pp. 106-111, 2005.

[72] E. C. Murru and K. A. M. Ginis, "Imagining the possibilities: the effects of a possible selves intervention on self-regulatory efficacy and exercise behavior," Journal of Sport and Exercise Psychology, vol. 32, no. 4, pp. 537-554, 2010.

[73] A. R. Nicholls, R. Polman, and A. R. Levy, "Coping self-efficacy, pre-competitive anxiety, and subjective performance among athletes," European Journal of Sport Science, vol. 10, no. 2, pp. 97-102, 2010.

[74] C. R. Nigg and K. S. Courneya, "Transtheoretical model: examining adolescent exercise behavior," Journal of Adolescent Health, vol. 22, no. 3, pp. 214-224, 1998.

[75] C. R. Nigg, "Explaining adolescent exercise behavior change: a longitudinal application of the transtheoretical model," Annals of Behavioral Medicine, vol. 23, no. 1, pp. 11-20, 2001.

[76] G. S. Parcel, B. Simons-Morton, N. M. O’Hara, T. Baranowski, and B. Wilson, "School promotion of healthful diet and physical activity: impact on learning outcomes and self-reported behavior," Health Education Quarterly, vol. 16, no. 2, pp. 181-199, 1989.

[77] K. Patrick, J. F. Sallis, J. J. Prochaska et al., "A multicomponent program for nutrition and physical activity change in primary care: PACE+ for adolescents," Archives of Pediatrics and Adolescent Medicine, vol. 155, no. 8, pp. 940-946, 2001.

[78] N. J. Pender, O. Bar-Or, B. Wilk, and S. Mitchell, "Selfefficacy and perceived exertion of girls during exercise," Nursing Research, vol. 51, no. 2, pp. 86-91, 2002.

[79] L. M. Quintiliani, M. K. Campbell, J. M. Bowling, S. Steck, P. S. Haines, and B. M. Devellis, "Results of a randomized trial testing messages tailored to participantselected topics among female college students: physical activity outcomes," Journal of Physical Activity and Health, vol. 7, no. 4, pp. 517-526, 2010.

[80] L. Raudsepp, R. Viira, and A. Hannus, "Prediction of physical activity intention and behavior in a longitudinal sample of adolescent girls," Perceptual and Motor Skills, vol. 110, no. 1, pp. 3-18, 2010.

[81] B. Renner, Y. Spivak, S. Kwon, and R. Schwarzer, "Does age make a difference? Predicting physical activity of South Koreans," Psychology and Aging, vol. 22, no. 3, pp. 482-493, 2007.

[82] L. B. Robbins, N. J. Pender, D. L. Ronis, A. S. Kazanis, and M. B. Pis, "Physical activity, self-efficacy, and perceived exertion among adolescents," Research in Nursing and Health, vol. 27, no. 6, pp. 435-446, 2004.

[83] L. B. Robbins, H. C. Talley, T. Y. Wu, and J. Wilbur, "Sixth-grade boys' perceived benefits of and barriers to physical activity and suggestions for increasing physical activity," Journal of School Nursing, vol. 26, no. 1, pp. 65-77, 2010. 
[84] J. N. Roemmich, C. M. Gurgol, and L. H. Epstein, "Influence of an interpersonal laboratory stressor on youths' choice to be physically active," Obesity Research, vol. 11, no. 9, pp. 1080-1087, 2003.

[85] J. N. Roemmich, C. M. Gurgol, and L. H. Epstein, "Open-loop feedback increases physical activity of youth," Medicine and Science in Sports and Exercise, vol. 36, no. 4, pp. 668-673, 2004.

[86] D. E. Rosenberg, G. J. Norman, J. F. Sallis, K. J. Calfas, and K. Patrick, "Covariation of adolescent physical activity and dietary behaviors over 12 months," Journal of Adolescent Health, vol. 41, no. 5, pp. 472-478, 2007.

[87] R. M. Ryan, C. M. Frederick, D. Lepes, N. Rubio, and K. M. Sheldon, "Intrinsic motivation and exercise adherence," International Journal of Sport Psychology, vol. 28, no. 4, pp. 335354, 1997.

[88] G. Ryan and D. Dzewaltowski, "Comparing the relationships between different types of self efficacy and physical activity in youth," Health Education and Behavior, vol. 29, no. 4, pp. 491504, 2002.

[89] J. F. Sallis, M. F. Hovell, and C. R. Hofstetter, "Predictors of adoption and maintenance of vigorous physical activity in men and women," Preventive Medicine, vol. 21, no. 2, pp. 237-251, 1992.

[90] J. F. Sallis, W. C. Taylor, J. J. Prochaska, J. O. Hill, and J. C. Geraci, "Correlates of physical activity in a national sample of girls and boys in grades 4 through 12," Health Psychology, vol. 18, no. 4, pp. $410-415,1999$.

[91] J. Salmon, K. Ball, C. Hume, M. Booth, and D. Crawford, "Outcomes of a group-randomized trial to prevent excess weight gain, reduce screen behaviours and promote physical activity in 10-year-old children: switch-play," International Journal of Obesity, vol. 32, no. 4, pp. 601-612, 2008.

[92] S. J. Salvy, J. Wojslawowicz-Bowker, J. N. Roemmich et al., "Peer influence on children's physical activity: an experience sampling study," Journal of Pediatric Psychology, vol. 33, no. 1, pp. 39-49, 2008.

[93] M. Schneider, G. F. Dunton, and D. M. Cooper, "Physical activity and physical self-concept among sedentary adolescent females: an intervention study," Psychology of Sport and Exercise, vol. 9, no. 1, pp. 1-14, 2008.

[94] N. Sherwood, C. Wendell, M. Treuth, L. Klesges, T. Baranowski, A. Zhou et al., "Measurement characteristics of activity-related psychosocial measures in 8 to 10 year old African-American girls in the girls health enrichment multisite study (GEMS)," Preventative Medicine, vol. 38, supplement, pp. S60-S68, 2004.

[95] C. A. Shields, K. S. Spink, K. Chad, N. Muhajarine, L. Humbert, and P. Odnokon, "Youth and adolescent physical activity lapsers: examining self-efficacy as a mediator of the relationship between family social influence and physical activity," Journal of Health Psychology, vol. 13, no. 1, pp. 121-130, 2008.

[96] C. A. Shields and L. R. Brawley, "Preferring proxy-agency: impact on self-efficacy for exercise," Journal of Health Psychology, vol. 11, no. 6, pp. 904-914, 2006.

[97] T. L. Shrigley and K. A. Dawson, "Understanding the role of behavior and cognitions in a group exercise setting," Journal of Sports Science and Medicine, vol. 3, pp. 56-61, 2004.

[98] M. S. Sothern, S. Hunter, R. M. Suskind, R. Brown, J. N. Udall, and U. Blecker, "Motivating the obese child to move: the role of structured exercise in pediatric weight management," Southern Medical Journal, vol. 92, no. 6, pp. 577-584, 1999.

[99] E. Stone, T. McKenzie, G. Welk, and M. Booth, "Effects of physical activity interventions in youths: review and synthesis,"
American Journal of Preventative Medicine, vol. 15, no. 4, pp. 298-315, 1998.

[100] R. S. Strauss, D. Rodzilsky, G. Burack, and M. Colin, "Psychosocial correlates of physical activity in healthy children," Archives of Pediatrics and Adolescent Medicine, vol. 155, no. 8, pp. 897902, 2001.

[101] R. Y. T. Sung, C. W. Yu, R. C. H. So, P. K. W. Lam, and K. T. $\mathrm{Hau}$, "Self-perception of physical competences in preadolescent overweight Chinese children," European Journal of Clinical Nutrition, vol. 59, no. 1, pp. 101-106, 2005.

[102] I. M. Taylor, N. Ntoumanis, M. Standage, and C. M. Spray, "Motivational predictors of physical education students' effort, exercise intentions, and leisure-time physical activity: a multilevel linear growth analysis," Journal of Sport and Exercise Psychology, vol. 32, no. 1, pp. 99-120, 2010.

[103] P. Taymoori and D. R. Lubans, "Mediators of behavior change in two tailored physical activity interventions for adolescent girls," Psychology of Sport and Exercise, vol. 9, no. 5, pp. 605-619, 2008.

[104] P. Taymoori, D. Lubans, and T. R. Berry, "Evaluation of the health promotion model to predict physical activity in iranian adolescent boys," Health Education and Behavior, vol. 37, no. 1, pp. 84-96, 2010.

[105] J. L. Thompson, S. M. Davis, J. Gittelsohn et al., "Patterns of physical activity among American Indian children: an assessment of barriers and support," Journal of Community Health, vol. 26, no. 6, pp. 423-445, 2001.

[106] S. G. Trost, R. R. Pate, R. Saunders, D. S. Ward, M. Dowda, and G. Felton, "A prospective study of the determinants of physical activity in rural fifth-grade children," Preventive Medicine, vol. 26, no. 2, pp. 257-263, 1997.

[107] S. G. Trost, R. R. Pate, D. S. Ward, R. Saunders, and W. Riner, "Correlates of objectively measured physical activity in preadolescent youth," American Journal of Preventive Medicine, vol. 17, no. 2, pp. 120-126, 1999.

[108] R. F. Valois, M. R. Umstattd, K. J. Zullig, and R. J. Paxton, "Physical activity behaviors and emotional self-efficacy: is there a relationship for adolescents?" Journal of School Health, vol. 78, no. 6, pp. 321-327, 2008.

[109] K. Watson, T. Baranowski, D. Thompson, R. Jago, J. Baranowski, and L. M. Klesges, "Innovative application of a multidimensional item response model in assessing the influence of social desirability on the pseudo-relationship between self-efficacy and behavior," Health Education Research, vol. 21, pp. 85-97, 2006.

[110] D. K. Wilson, S. Griffin, R. P. Saunders et al., "Formative evaluation of a motivational intervention for increasing physical activity in underserved youth," Evaluation and Program Planning, vol. 29, no. 3, pp. 260-268, 2006.

[111] D. K. Wilson, H. Kitzman-Ulrich, J. E. Williams et al., "An overview of "the active by choice today" (ACT) trial for increasing physical activity," Contemporary Clinical Trials, vol. 29, no. 1, pp. 21-31, 2008.

[112] P. J. Wenthe, K. F. Janz, and S. M. Levy, "Gender similarities and differences in factors associated with adolescent moderatevigorous physical activity," Pediatric Exercise Science, vol. 21, no. 3, pp. 291-304, 2009.

[113] P. M. Wright, S. Ding, and W. Li, "Relations of perceived physical self-efficacy and motivational responses toward physical activity by urban high school students," Perceptual and Motor Skills, vol. 101, no. 2, pp. 651-656, 2005. 


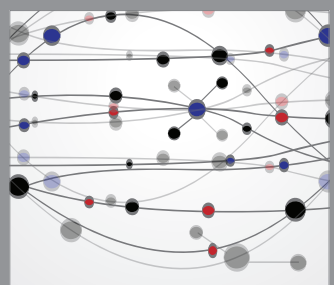

The Scientific World Journal
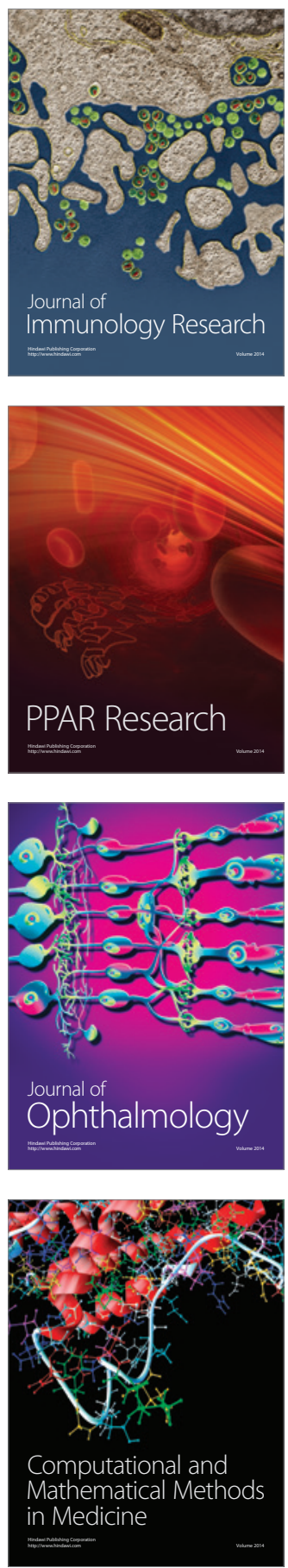

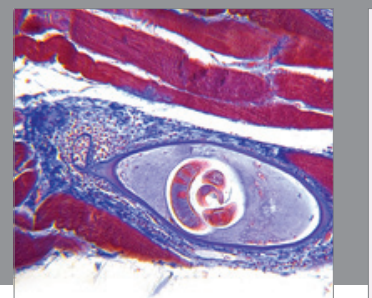

Gastroenterology

Research and Practice
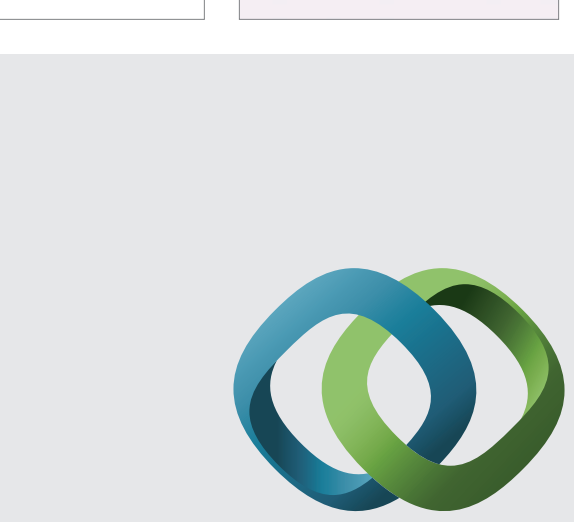

\section{Hindawi}

Submit your manuscripts at

http://www.hindawi.com
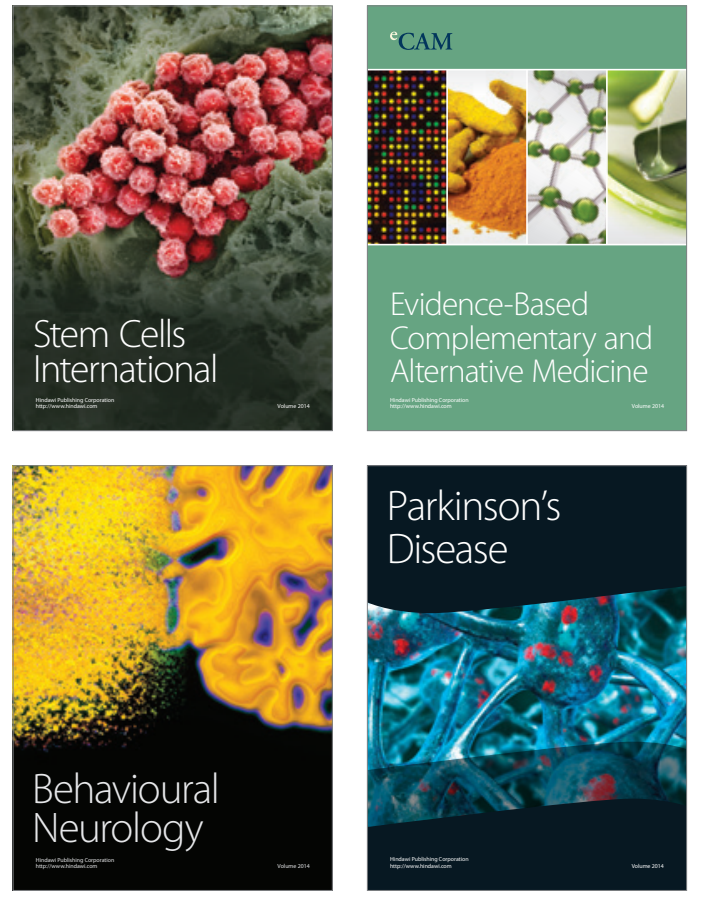
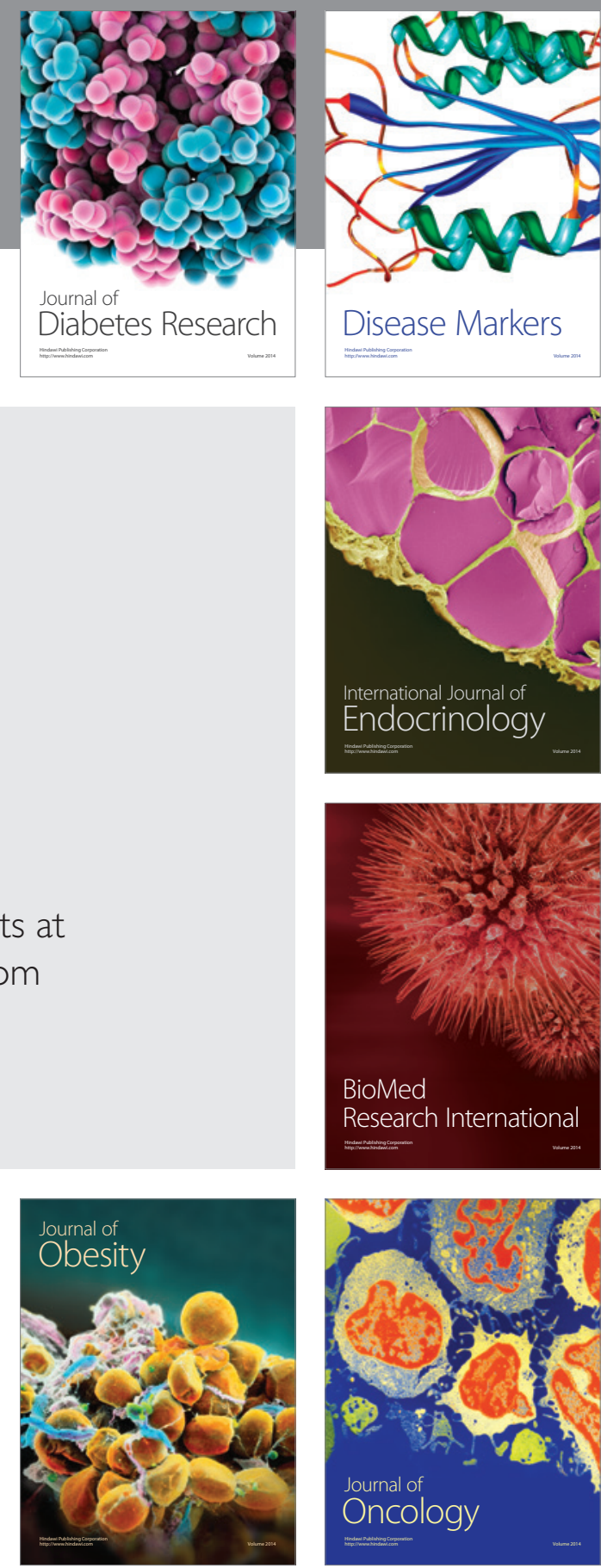

Disease Markers
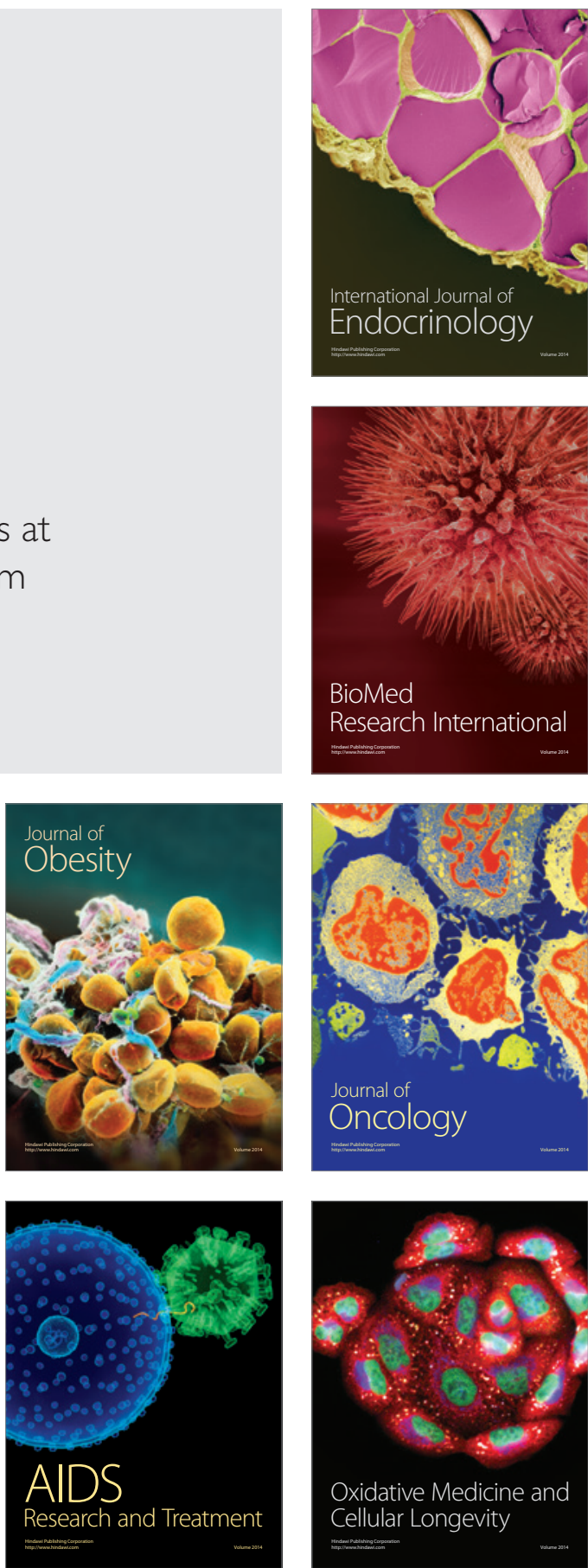